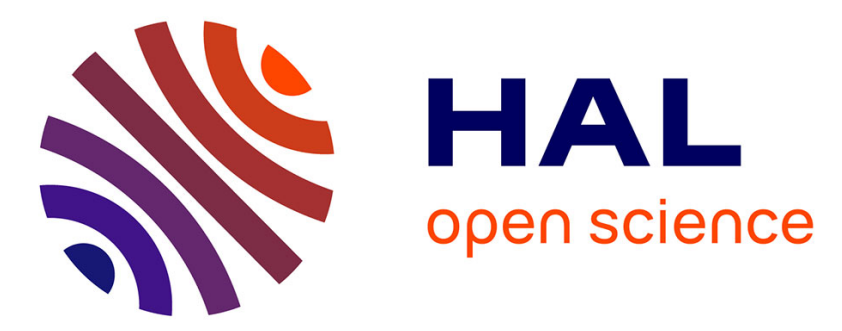

\title{
Smart Manufacturing: Characteristics and Technologies
}

Sameer Mittal, Muztoba Ahmad Khan, Thorsten Wuest

\section{To cite this version:}

Sameer Mittal, Muztoba Ahmad Khan, Thorsten Wuest. Smart Manufacturing: Characteristics and Technologies. 13th IFIP International Conference on Product Lifecycle Management (PLM), Jul 2016, Columbia, SC, United States. pp.539-548, 10.1007/978-3-319-54660-5_48 . hal-01699678

\section{HAL Id: hal-01699678 https://hal.inria.fr/hal-01699678}

Submitted on 2 Feb 2018

HAL is a multi-disciplinary open access archive for the deposit and dissemination of scientific research documents, whether they are published or not. The documents may come from teaching and research institutions in France or abroad, or from public or private research centers.
L'archive ouverte pluridisciplinaire HAL, est destinée au dépôt et à la diffusion de documents scientifiques de niveau recherche, publiés ou non, émanant des établissements d'enseignement et de recherche français ou étrangers, des laboratoires publics ou privés.

\section{(c)(1)}

Distributed under a Creative Commons Attribution| 4.0 International License 


\title{
Smart Manufacturing: Characteristics and Technologies
}

\author{
Sameer Mittal ${ }^{1}$, Muztoba Ahmad Khan ${ }^{1}$ and Thorsten Wuest ${ }^{1}$ \\ ${ }^{1}$ Department of Industrial and Management Systems Engineering, West Virginia University, \\ Morgantown, West Virginia, USA \\ \{samittal,mdkhan\}@mix.wvu.edu; thwuest@mail.wvu.edu
}

\begin{abstract}
The purpose of this paper is to collect and structure the various features of Smart Manufacturing (SM). Researchers have previously identified various characteristics and technologies of Smart Manufacturing System (SMS); this paper collects, discusses and merges some of those characteristics and technologies available in the current body of knowledge. In the future, it is expected that this selection of characteristics and technologies will help to compare and distinguish other initiatives like Industry 4.0, smart factory, intelligent manufacturing, distributive manufacturing, etc. which are frequently used synonymous with SM. The result of this paper is a comprehensive list of characteristics and technologies that are associated with a SMS. As many of the listed items show variating overlaps, certain technologies and characteristics are merged and clustered. This results in a set of five defining characteristics and ten technologies that are considered relevant for a SMS. The authors hope to provide a basis for a broad and interdisciplinary discussion within the SM community about the defining technologies and characteristics of a SMS.
\end{abstract}

Keywords: Smart Manufacturing, Characteristics and Technologies, Industry 4.0, Smart Factory, Intelligent Manufacturing.

\section{Introduction}

Smart Manufacturing (SM) has significant gained momentum in industry and academia in recent years. SM is set of practices that use networked data and information technology [1], [2] to architect the future manufacturing systems. Many manufacturing systems are presenting themselves as Smart Manufacturing Systems (SMS). However, there is still a lack of commonly accepted understanding what defines a manufacturing system as being 'smart'.

What aspects make a manufacturing system smart? Literature suggests to consider these aspects in the form of characteristics and technologies. Only two papers were found relevant to the list of characteristics and technologies associated with smart manufacturing when we used "Smart Manufacturing" as the search term in the electronic journals of Taylor and Francis, Science Direct, Wiley, Emerald and Springer. We did the same at Google and Google Scholar, and found only one relevant journal paper and few grey papers published by NIST (National Institute of 
Standards and Technology) and SMLC (Smart Manufacturing Leadership Coalition). In this study, we focused on characteristics and technologies of only SMS; and kept characteristics and technologies associated with Industry 4.0, smart factory and other such manufacturing initiatives out of our focus. The reason is, that this allows us to create a comprehensive list of SM-specific characteristics and technologies, which later may be compared to the aforementioned other concepts to analyze the similarities and differences among them.

This paper starts with the literature review of a comprehensive list of various characteristics and technologies that are associated with SMS. Later on, it discusses the individual characteristics and technologies and suggests a clustering based on their definition. Finally it concludes by presenting a more compact list of characteristics and technologies that are associated with SM as a basis for further discussion within the SM community.

\section{$2 \quad$ Literature Review}

Various researchers have identified different characteristics and technologies associated with SMS. Some of these characteristics and technologies have been specifically mentioned as such and the authors identified others by thoroughly going through the content. Depending on the application of SM, it may need a different set of characteristics and technologies. Therefore, the question arises if a SMS has to incorporate all of the identified characteristics and technologies simultaneously or if it is enough to define a manufacturing system as smart when only a certain selection is employed.

A characteristic is a property that is peculiar to something and can be varied to make elements look similar or different for example modularity, heterogeneity, flexibility, etc. Technology on the other hand is the use of science for practical purposes for example data analytics, 3-D printing, etc. Technology are also the identifiable parts of a larger construction that can provide a particular function or a group of related functions. This paper presents a discussion on various SM related characteristics and technologies that have been defined in the following section.

Table 1 presents a list of 19 characteristics identified in literature defining a SMS. The last column 'Cluster' in Table 1 will be elaborated in the discussion section. In Table 1 the characteristics have been shown in italic font and the technologies have been represented in bold font to make the paper more communicative to the readers.

Table 1. List of characteristics associated with a Smart Manufacturing System.

\begin{tabular}{|c|c|c|c|}
\hline SI. No. & Characteristic & Reference(s) & Cluster \\
\hline 1 & Digital Presence & {$[3],[4]$} & Context Awareness \\
\hline 2 & Modularity & {$[4]$} & Modularity \\
\hline 3 & Heterogeneity & {$[3],[4]$} & Heterogeneity \\
\hline 4 & Scalability & {$[3],[4]$} & Intelligent Control \\
\hline 5 & Context Awareness & {$[4]$} & Context Awareness \\
\hline 6 & Autonomy & {$[3],[4]$} & Intelligent Control \\
\hline
\end{tabular}




\begin{tabular}{|c|c|c|c|}
7 & Adaptability & {$[3]$} & Intelligent Control \\
\hline 8 & Robustness & {$[5]$} & Intelligent Control \\
\hline 9 & Flexibility & {$[6]$} & Intelligent Control \\
\hline 10 & Fully Automated & {$[6]$} & Intelligent Control \\
\hline 11 & Asset Self-awareness & {$[5]$} & Context Awareness \\
\hline 12 & Interoperability & {$[3],[4]$} & Interoperability \\
\hline 13 & Networkability & {$[4]$} & Interoperability \\
\hline 14 & Information Appropriateness & {$[5]$} & Interoperability \\
\hline 15 & Integrability & {$[5]$} & Interoperability \\
\hline & & & Energy saving/ Energy \\
& & {$[5]$} & Efficiency \\
\hline 16 & Sustainability & {$[3]$} & Compositionality \\
\hline 17 & Compositionality & {$[3]$} & Modularity \\
\hline 18 & Composability & {$[5]$} & Intelligent Control \\
\hline
\end{tabular}

Table 2 presents a list of 19 technologies that are associated with SMS. The last column in Table 1 has been framed after the discussion. Similar to the previous Table 1 , certain items can be identified as being rather closely related. This is partly due to different authors using different terminology but also the level of detail the authors chose to describe relevant subcategories of technologies. This issue will be addressed in the following discussion section. As in Table 1, the technology cluster in Table 2 are shown in bold.

Table 2. List of technologies associated with a Smart Manufacturing system.

\begin{tabular}{|c|c|c|c|}
\hline S. No. & Technology & Reference(s) & Cluster \\
\hline 1 & Intelligent & {$[6]$} & Intelligent Control \\
\hline 2 & Intelligent Control & {$[6]$} & Intelligent Control \\
\hline 3 & Energy Saving/ Energy Efficiency & {$[3],[7],[6]$} & $\begin{array}{c}\text { Energy saving/ } \\
\text { Energy Efficiency }\end{array}$ \\
\hline 4 & Cyber Security & {$[7],[5]$} & Cyber Security \\
\hline 5 & Holograms & {$[6],[7]$} & Visual Technology \\
\hline 6 & VR (Virtual Reality) & {$[7]$} & Visual Technology \\
\hline 7 & AR (Augmented Reality) & {$[7]$} & Visual Technology \\
\hline & Real-time Communication & {$[6]$} & Cloud \\
Manufacturing
\end{tabular}




\begin{tabular}{|c|c|c|c|} 
& & & $\begin{array}{c}\text { Additive } \\
\text { Manufacturing }\end{array}$ \\
\hline 16 & Tracking and Tracing & {$[6]$} & Smart Product/Part \\
\hline 17 & Smart Sensors & {$[6]$} & Smart Product/Part \\
\hline 18 & Smart Product/ Part & {$[6]$} & Smart Product/Part \\
\hline 19 & Data Analytics & {$[3],[4]$} & Data Analytics \\
\hline
\end{tabular}

The items presented in the Table 1 and 2 are derived from various literature sources. As mentioned, this leads to some of these items being similar. In the next section, we present a perspective on how we may cluster different characteristics and technologies.

\section{Discussion}

The presented characteristics and technologies have been mentioned and described in current SM literature. However, the detailed definitions of these characteristics and technologies suggest that some of them might be synonyms of each other and some of these may be merged to present a more focused result. In the following, the previously identified characteristics and technologies (Table $1 \& 2$ ) will be critically discussed and a clustering is proposed to develop a more comprehensive and targeted list. This is depicted in the fourth column in Table 1 and 2, which indicates the suggested clusters for each characteristic and technology. In the forthcoming analysis, the following format has been chosen for better illustration and transparency: characteristic cluster has been given the italics font whereas the technology cluster has been mentioned in bold font; similarly, to enhance the readability of the paper we have discussed them using the italics and bold fonts respectively.

\subsection{Characteristics Clusters}

Context Awareness: Context awareness is an important characteristic of a SMS [4] [8] and it can be seen as a combination of different attributes. Identity- A SMS should have a unique identity. As a SMS often operates in a digital environment, we may say that a SMS should have its own digital presence [4] and therefore digital presence is inherent when we consider context awareness. Location- It is used to describe the physical location of the system itself or subsystems within. Status- This is used to describe the present state of the activities that are being carried within the SMS. Asset self-awareness will also mean that the SMS should be able to know about its present state [5]. Time: The SMS should be able to define its timely priorities, and it might even need to consider the local time.

Modularity: Modularity is the property of a system, by virtue of which a unit can be decomposed into components that can be combined to form different configurations [4]. Composability is the property of the system when it could be developed from its 
sub-systems [3]. As both of these properties consider a unit being made from subunits and by modularity we can have a different unit arising, therefore composability may be considered as a part of modularity.

Heterogeneity: Heterogeneity considers the diversity and dissimilarities in the units and components. However, it does not consider the combination of units and as a result it should be considered as a separate characteristic [4].

Compositionality: Compositionality is the property that deals with the understanding of the whole system based on the definition of its components and the combination of the constituents [3]. As, neither modularity nor heterogeneity deal with the system or component definitions compositionality should be considered as a separate characteristic.

Interoperability: Interoperability is the characteristic due to which units would be able to exchange and share information with each other [4] [3]. With the help of networkability, systems are able to collaborate in different process related aspects and for this collaboration they have to allow each other to share and exchange their information [4]. Therefore, networkability is covered by interoperability. Information appropriateness, describes that information is available, accessible and understandable when needed; this should be a characteristic of information to be shared otherwise the information will be of no use [5]. Integrability is the characteristic due to which different units can be integrated, but two units are integrated if they have an access to each other's information and therefore this characteristic is included in interoperability [5]. However, integrability is different from modularity because modularity combines the systems physically resulting into a new configuration, whereas integrability is inclined towards the exchange of information between two systems and therefore it is a part of interoperability.

\subsection{Technologies Clusters}

Intelligent Control: An important characteristic of manufacturing is that the systems are very quick to response. Papers referred to this response using different words. Scalability is considered as the property by which it can easily handle the fluctuations in load [4], by adaptability it can decide about its own diagnosis, prognosis, and the best system performance even when it has uncertain information [9], a machine has robustness when under uncertain conditions it can perform well [5] and it possesses flexibility when it can adapt to changes in the external environment [10]. With the help of intelligent technology a system is able to change its action based on its own experience [11] and it has intelligent control technology than it can make use of artificial intelligence techniques to control its mechanisms [11]. These characteristics and technologies converge towards being responsive to changes and may use artificial intelligence techniques for doing so and therefore, they should be considered as a part of Intelligent Control. A manufacturing unit possess autonomy if a) it can adapt with feedback and pursue its activities to achieve the objective [4] and 
b) the unit wants the feedback mechanism to work it will need the technology of intelligent control therefore autonomy should be a part of intelligent control. A system is said to be fully automated if it can do its own work completely but the extent of automation may vary from system to system. For a system to be fully automated it will also need some intelligent control mechanisms and more sophisticated are the control mechanisms the degree of automation would increase. Therefore, fully automated should also be covered by intelligent control. Proactivity is the characteristic that can help units to eliminate failures before they happen by sensing the situation [5]. As, this characteristic considers sensing and controlling the mechanism of system, it will need intelligent control mechanism and therefore we can consider it as a part of intelligent control. But, proactivity senses the present situation that might involve data so this characteristic might be involved in the data analytics cluster as well.

Energy saving/ Energy Efficiency: Products and processes are said to possess sustainability if they are reusable and they cause minimum environmental footprints [5] thus making the products and processes more economical, social and environment friendly. Energy saving/ Energy Efficiency is the technology due to which the energy required to provide a product and service can be reduced and various studies have been done to decrease the use of energy in manufacturing systems [7]. If a system can reuse its products then the amount of energy required will decrease and therefore sustainability can be arguable seen as part of energy saving. Although, researchers have considered energy saving/ energy efficiency on par with the other technologies, it should be rather considered as a necessity for any manufacturing system and not only SMS. The choice of terminology 'energy saving' as a technology was derived from literature.

Cyber Security: Data should be secured from cyber threats. As SM is largely based on digitization and data based services, cyber security becomes an important technology for SMS [8]. Even though this also involves data, it should still be considered separate from interoperability because interoperability is about data sharing and availability whereas this is about data privacy and security.

Visual Technology: Hologram is the technology that makes use of a 3-D image formed by a light field in a three dimensional space [12]; Virtual Reality (VR) is a technology that creates 3-D image with the help of a computer and it can be interacted with the help of electronic devices and the user can feel as if he has been "immersed in a synthesized environment" [13][14]; Augmented Reality (AR) is a technology that can superimpose a computer generated 3-D numerical format in the real world, but one cannot interact with it [15][16]. Since all these technologies deal with the visual representation of an object they may be considered as a part of the visual technology cluster [15].

Data Analytics: Big data is the technology that can analyze large data sets including real-time data that is difficult to analyze by traditional methods; data analytics deal with turning the volume, variety, velocity and veracity of data into actions and insights in a manufacturing system [3] [16]. As data analytics can deal with a very 
high volume of data so big data can be placed under it and it can even deal with a high velocity of data therefore it can communicate in real-time with the customers.

Cyber Physical Infrastructure: Cyber-physical System (CPS)/ Cyber-Physical Production Systems (CPPS) are the same [3] and they are the technology used by computer algorithms to solve physical mechanisms [18]; CPPS is an applied form of CPS in production [19]. We will consider all these technologies as CPS.

IoT/ IoS: The IoT enables the communication between physical and internet-enabled devices [7] and when IoT capabilities are seen as services they are referred as IoS [20]. Although both CPS and IoT/IoS consider physical world but the computer algorithms may or may not use the internet. There are examples when CPS has been considered as a foundation for IoT/IoS [21]. But they might not always help each other so they are considered as separate technologies in this case. In this paper we are considering IoT as ubiquitous in the global sense and as a combination of national IoT, industrial IoT and local IoT [22].

Advanced Manufacturing: Advanced Manufacturing is the technology that can integrate technology based production systems like FMS (Flexible Manufacturing System), RMS (Reconfigurable Manufacturing System), CIM (Computer Integrated Manufacturing), Additive Manufacturing etc. [23]. Overall, advanced manufacturing may be understood as an integration of different production technologies and therefore it should not be considered as a technology for Smart Manufacturing. Rather it could be an important discussion if various advanced manufacturing systems could be referred to as SMS. One possible distinction is that SM are reliable on data analytics and the advanced manufacturing is more physical manufacturing-technology focused.

Cloud Manufacturing: Cloud Manufacturing is driven by cloud computing [16] that can, e.g., use real-time demand to decide the production planning and scheduling. Data analytics may be considered as a part of cloud manufacturing, but as the applications of data analytics are so diverse that we should not consider it to be a part of cloud manufacturing. Real-time communication is the technology that would enable the users to exchange data with the systems in real-time. As it involves exchange of information between system and humans therefore it is not a part of interoperability.

3-D Printing/ Additive Manufacturing: 3-D Printing/ Additive Manufacturing is the technology that can print a 3-D image into an object with the help of laser beam, electron beam etc., as the objects are printed layer by layer therefore this technology is also referred as additive manufacturing [8]. Additive Manufacturing is often referred to as being part of the Advanced Manufacturing domain [23].

Smart Products/ Parts: Tracking and tracing is the technology due to which one can find the past and present locations of unique objects as information carrying identities [24]. But we need some (sensing) technology which can help to monitor tracking and tracing, and these sensors are referred as smart sensors; when the smart sensors, have 
processors and software for an efficient exchange of data they are called as smart products/ parts. IT has not been considered as a separate technology as almost all other technologies need inputs from it. It may be argued that tracking and tracing is to be considered as a characteristic or a technology, but as it has been finally kept under a technology group and it has been considered as a technology [6]. Tracking and tracing could also be considered as Tracking and tracing in Real-time but in this paper Real-time communication is considered as a separate technology placed under Cloud Manufacturing and therefore it is rather referred as Tracking and tracing.

From our discussion we can observe that there are many characteristic act as the building block for a technology and therefore we have less number of characteristics and more number of technologies. It can also be seen that the cluster intelligent control consists of six characteristics namely scalability, adaptability, flexibility, autonomy, fully automated, proactivity and 2 technologies intelligent and intelligent control; making it the biggest cluster. It has also been discussed that why some of the technologies like data analytics and cloud manufacturing that have many common elements are being considered as separate?

Commercial implementation of SM for 4 different kind of industries has also been presented in the literature [1]. NIST has also presented some of the characteristics and technologies discussed in this paper and considered as standards. The list of aggregated characteristics and technology clusters presented in this paper is expanding on the basic ones presented in [25]. A landscape consisting of standards has also been suggested for reaching the goal of SM [25]. The standards are presented in terms of the three lifecycle dimensions: product, production system and business. Later, the standards that are present today and the one that are required in the future for establishing an SM are analyzed. These characteristics and definitions are from a small set of research and there might be some others which were not reviewed and in future we plan to consider a more comprehensive list.

\section{Conclusion}

This paper identified, discussed and clustered characteristics and technologies that define a Smart Manufacturing System (SMS). Overall, it was found that there are five characteristics, namely context awareness, modularity, heterogeneity, interoperability and compositionality, and ten technologies, namely intelligent control, energy saving/ energy efficiency, cyber security, CPS/CPPS, visual technology, IoT/IoS, cloud computing/ cloud manufacturing, 3-D printing/ additive manufacturing, smart product/ part and data analytics, that are required in a SMS. These characteristics and technologies can also be used to classify a manufacturing system as smart. With the help of this list of characteristics and technologies we can classify if the initiatives like Industry 4.0, and manufacturing systems like smart factory, intelligent manufacturing, distributive manufacturing, etc. are similar, and if by what degree, to smart manufacturing. In this paper, we can also observe that there is a smaller number of clustered characteristics compared to the number of clustered technologies. One 
possible explanation for this is, that technologies needed some characteristics as their inputs and it would have been redundant to consider such characteristics separately, for example the characteristics scalability, flexibility, adaptability, robustness, autonomy, fully automated and proactivity were clustered in the technology intelligent control. However, for the same reason we do not have technology/technologies clustering into a characteristic. It was also discussed why advanced manufacturing is a manufacturing system itself and should not be considered as a part of technologies.

The resultant list is to be understood as a first step in defining a comprehensive list of commonly agreed upon SM characteristics and technologies. The authors encourage industry and academic SM professionals to provide feedback in order to develop this list further. This can lead to a further expansion or reduction of the list. A similar development is expected if new SM literature will be published in the future containing additional characteristics and technologies.

A limitation of this paper is that, while extracting the characteristics and technologies from literature sources where they were not directly mentioned and classified as such, the subjective perspective of authors plays a part in the decision of choosing either technology or characteristic as the defining element. The clusters made here were made by the knowledge and perspective of the authors. Some of the characteristics and technologies were listed in the literature but there definitions were not provided and therefore these characteristics and technologies were defined from other papers and author's knowledge. The authors tried to increase the transparency of the clustering by explaining the reasoning of the decisions. However, this paper is understood as a first step towards a commonly accepted list of defining characteristics and technologies for Smart Manufacturing. Readers are actively encouraged to provide feedback and challenge the selection.

\section{References}

1. Davis, J., Edgar, T., Graybill, R., Korambath, P., Schott, B., Swink, D., Wang, J. and Wetzel, J.: Smart Manufacturing. In: Annual review of chemical and biomolecular engineering, vol. 6, pp. 141-160 (2015)

2. Smart Manufacturing Leadership Coalition, https://smartmanufacturingcoalition.org/ (visited on 05/30/2016)

3. Rachuri, S.: Smart Manufacturing Systems Design and Analysis. In: National Institute of Standards and Technology (2015)

4. Kühnle, H., Bitsch, G.: Smart Manufacturing Units. In: Foundations \& Principles of Distributed Manufacturing, pp. 55-70. Springer International Publishing (2015)

5. Smart Process Manufacturing Engineering Virtual Organization Steering Committee: Smart process manufacturing: an operations and technology roadmap. Full Report (2009)

6. Park, J., Lee, J.: Presentation on Korea smart factory program. In: $12^{\text {th }}$ International Conference on Advances in Production Management Systems. (presentation on 09/08/2015)

7. Kang, H.S., Lee, J.Y., Choi, S., Kim, H., Park, J.H., Son, J.Y., Do Noh, S.: Smart manufacturing: Past research, present findings, and future directions. In: International Journal of Precision Engineering and Manufacturing-Green Technology, vol. 3, pp. 111128. Springer, Berlin, Germany (2016) 
8. Abowd, G.D., Ebling, M., Hung, G., Lei, H., Gellersen, H.W.: Context- aware computing [Guest Editors' Intro.]. Pervasive Computing, IEEE, vol. 1, pp. 22-23 (2002)

9. Zuehlke, D.: SmartFactory-Towards a factory-of-things. In: Annual Reviews in Control, vol. 34, pp. 129-138 (2010)

10. De Weck, O.L., Ross, A.M., Rhodes, D.H.: Investigating relationships and semantic sets amongst system lifecycle properties (Ilities). In: Third international engineering systems symposium CESUN, vol. 1, pp. 18-20 (2012)

11. Stengel, R.: Robotics and Intelligent Systems! (2015)

12. Matsushima, K., Nakahara, S., Arima, Y., Nishi, H., Yamashita, H., Yoshizaki, Y., Ogawa, K.: Computer holography: 3D digital art based on high-definition CGH. In: Journal of Physics: Conference Series, vol. 415, pp. 12-53. IOP Publishing (2013)

13. Steuer, J.: Defining virtual reality: Dimensions determining telepresence. In: Journal of communication, vol. 42, pp. 73-93 (1992)

14. Earnshaw, R.A.: Virtual reality systems. Academic press (2014)

15. Azuma, R.T.: A survey of augmented reality. In: Teleoperators and virtual environments, vol. 6, pp. 355-385 (1997)

16. Yu, C., Xu, X., Lu, Y.: Computer-Integrated Manufacturing, Cyber-Physical Systems and Cloud Manufacturing-Concepts and relationships. In: Manufacturing Letters, vol. 6, pp. 59 (2015)

17. Salehan, M., Kim, D. J.: Predicting the performance of online consumer reviews: A sentiment mining approach to big data analytics. In: Decision Support Systems, vol. 81, pp. 30-40 (2016)

18. Lee, Edward A.: Cyber physical systems: Design challenges. In: $11^{\text {th }}$ IEEE International Symposium on Object Oriented Real-Time Distributed Computing, pp. 363-369 (2008)

19. Monostori, L. Cyber-physical production systems: Roots, expectations and R\&D challenges. In: Procedia CIRP, vol. 17, pp. 9-13. Elsevier (2014)

20. Alberti, A.M., Singh, D. Internet of Things: Perspectives, Challenges and Opportunities. In: International Workshop on Telecommunications, pp. 1-6 (2013)

21. Klotzer, C., Pflaum, A.: Cyber-physical systems as the technical foundation for problem solutions in manufacturing, logistics and supply chain management. In: 5th International Conference on Internet of Things (IOT), pp. 12-19. IEEE (2015)

22. Ning, H., Wang, Z.: Future internet of things architecture: like mankind neural system or social organization framework? In: Communications Letters, vol. 15, pp. 461-463. (2011)

23. Tao, F., Cheng, Y., Zhang, L., Nee, A.Y.C.: Advanced manufacturing systems: socialization characteristics and trends. In: Journal of Intelligent Manufacturing, vol. 1, pp. 1-16 (2014)

24. Paunescu, D., Stark, W. J., \& Grass, R. N.: Particles with an identity: Tracking and tracing in commodity products. In: Powder Technology, vol. 291, pp. 344-350 (2016)

25. Lu, Y., Marris, KC \& Frechette, S. (2016). Current Standards Landscape for Smart Manufacturing Systems. (NISTIR 8107). doi: 10.6028/NIST.IR.8107 